\title{
Numerical investigation of the cold-formed I-beams bending strength with different web shapes
}

\author{
Nadia Kouider, Yazid Hadidane \\ Civil Engineering Laboratory, Badji Mokhtar-Annaba University, P. O. Box 12, 23000 Annaba, Algeria \\ nadia.kouider23@gmail.com,nadia.kouider@univ-annaba.dz. \\ y.hadidane@gmail.com
}

Mohammed. Benzerara

Materials, Geomaterials and Environment Laboratory, Department of Civil Engineering, Badji Mokbtar- Annaba University, P. O. Box 12, 23000 Annaba, Algeria

Institut de Recherche Dupuy de Lôme (IRDL), UMR CNRS 6027, Université Bretagne-Sud, F-56100 Lorient, France

mobammed.benzerara@univ-annaba.org

mohammed.benzerara@univ-ubs.fr

ABSTRACT. The wide use of cold-formed sections (CFS) in the field of steel constructions, favored by the multiple advantages they offer (lightness, ease of installation, etc.), has led us to reflect on a new process for manufacture of metal beams allowing the design of very large span hangars and a reduction in instability problems. This paper presents a study of the theoretical and numerical behavior of a large span CFS beam with different webs, a solid web, a triangular corrugated web, and a trapezoidal corrugated web. These beams are stressed by a concentrated bending load at mid-span. Numerical modeling was done using the finite element software ABAQUS. The numerical results have been validated by the analytical results those obtained based on Eurocode 3. The load capacity and failure modes of the beams were discussed. According to numerical and analytical analysis, corrugated web beams perform better than all other sections.

KEYwORDS. Cold formed sections; Corrugated webs; Finite element models; Bending test; Failure modes.

\section{OPEN ACCESS}

Citation: Kouider, N., Hadidane, Y., Benzerara, M., Numerical investigation of the cold-formed I-beams bending strength with different web shapes, Frattura ed Integrità Strutturale, 59 (2022) 153-171.

Received: 30.08 .2021

Accepted: 15.10 .2021 Published: 01.01.2022

Copyright: (C) 2022 This is an open access article under the terms of the CC-BY 4.0, which permits unrestricted use, distribution, and reproduction in any medium, provided the original author and source are credited.

\section{INTRODUCTION}

S tructural elements in steel construction are classified into two categories: hot-rolled sections and cold-formed sections. Cold-formed steel sections (CFS) are preferable to hot-rolled sections because of their greater versatility and because they are well suited to be economically constructed [1]. Cold formed steel is also known as light steel. In the field of civil engineering, cold-formed steel elements are generally used in industrial buildings as purlins, columns, trellises or structural members, storage supports, vehicle bodies, and various types of equipment [2]. In recent years, the use of CFS 
structures has increased rapidly due to significant improvements in manufacturing technologies. CFS elements are made from steel sheets and are formed into different shapes, either by press bending of sheared sheets or coils or, more commonly, by rolling at room temperature [3,4]. Structural elements in CFS retain their position in the light construction sector. This is due to the important advantages of CFS: high strength/weight ratio, ease of transport, the possibility of using all conventional assembly methods, cost efficiency, very good quality control, dimensional stability, and flexibility in the manufacture of profiles by compared to hot-rolled sections [5,6].

In thin-walled or cold-formed steel sections, the width/thickness ratio of the plate elements is always important and the bending failure occurs by buckling and not by deformation, which limits its loading capacity [7]. Generally, cold formed steel sections such as $\mathrm{U}, \mathrm{Z}$, and I sections are effectively used as bending elements for purlins, wall grids, and roof slabs [8]. The strength of the elements used in the design is generally governed by buckling. They are commonly referred to as "light gauge sections" because their thickness is normally less than $12.0 \mathrm{~mm}$. However, more recent developments have made it possible to form cold sections up to $25 \mathrm{~mm}$ thick, and open sections with a thickness of around $8 \mathrm{~mm}$ are becoming common in building construction. The steel used for these sections can have a yield strength ranging from $250 \mathrm{MPa}$ to $550 \mathrm{MPa}$. The elasticity value is increased from 15 to $30 \%$ [9].

In steel constructions, I sections are normally used as beams and columns. The current form of this beam is constructed from two parallel flanges a smooth web. One of the recent developments in construction technology is the use of the corrugated core instead of a solid core [10]. Corrugated web beams have been used for steel buildings and road bridges in Europe since the early 1960s and for road bridges in Europe and Japan since the 1980s [11]. In addition, the shear stresses which develop due to external loads are taken up by thin cores. If the web of an I-section is unstable (buckling), stiffeners can also be used to compensate for stability issues. To eliminate the use of stiffeners, corrugations in the web portion can be provided as a solution as this corrugated web provides greater lateral stiffness compared to flat webs $[10,12]$.

CFS members are known as members subject to local, global buckling instabilities and strain, even at stress levels below the yield point. To minimize buckling instabilities by eliminating free edges, cross sections have been developed and subjected to extensive studies to find their varying structural behavior in the context of bending, shearing, and crushing of the web [13].

Corrugated web beams are advantageous for the construction industry, due to the maximum lateral stiffness of the beam. The corrugated core can be sinusoidal, triangular [14], trapezoidal and rectangular) [3,11]. A corrugated core beam is constructed with thin-walled corrugated cores and wing plates. The profiling of the webs avoids the rupture of the beam due to the loss of stability before the plastic limit load of the webs is reached (class 4). The main assumptions for corrugated steel plates are negligible bending capacity with adequate out-of-plane stiffness [8].

In the literature, many researchers have attempted to use corrugated plates in the webs of hot-rolled I-beams. This overcomes the drawbacks of conventional stiffened flat cores. Such as web instability due to bending stress and fatigue failure. Previous researchers studied I-beams with trapezoidal corrugation for hot-rolled sections. Abbas and al [11] treated a comparison between a beam with a trapezoidal web and the other a beam with a sinusoidal web, comparing with an I beam. The work confirms that corrugated webs have better shear stability and fatigue resistance compared to the standard flat web I-beam. Sumathi and al [1] showed a study of the behavior of a CFS with a solid web, a triangular corrugated web, and a trapezoidal corrugated web. This study involves the examination of theoretical and experimental investigations of serial specimens. Altogether three specimens were tested with a length of $1200 \mathrm{~mm}$, they are tested under two points bending load with single support condition. Theoretical data used by Sumathi and al are calculated using the Indian standard code IS 801-1975 [1]. In our study, the numerical model was validated by the theoretical model, which is based on the calculation code Eurocode 3. It was found that the beam with a trapezoidal corrugation embedded web of 300 and 450 not only increases the load capacity but also the bearing capacity compared to the beam with a smooth web in the work of Divahar and al [8]. The use of cold corrugated webs makes it possible to increase the buckling rigidity of the beams where the folds will play the role of stiffeners. Thus, the use of these corrugated sheets will make it possible to lighten the beams, which will lead to a gain in weight (low thickness) and application to beams of great range.

\section{THEORETICAL METHOD}

$\mathrm{I}$ $\mathrm{n}$ order to have an economic effect of the use of bent profiles in constructions, it is necessary to study new optimal cross-sectional shapes, new calculation methods, new construction, and assembly technologies. This reason led us to think about a new process for manufacturing large span metal beams $(12 \mathrm{~m})$ of form I allowing the design of hangars. These beams are made by a welded assembly of plates and cold folded sheets. 
The dimensional characteristics are shown in Fig. 1 and the verification of the geometric proportions are presented in the following formulas [15]:

$$
\begin{aligned}
& b_{p}=b-t_{n o m} \\
& b_{p 1}=b_{p 2}=b-t_{n o m} \\
& C_{p 1}=C_{p 2}=C_{p 3}=C_{p 4}=C-t_{n o m}
\end{aligned}
$$

Regarding the minimum thickness to be used, Eurocode 3 part 1-3 proposes the following values [15]:

$$
\begin{aligned}
& 1.0 \mathrm{~mm} \leq t \leq 4.0 \mathrm{~mm} \\
& \frac{b f}{t} \leq 60 \\
& \frac{b}{t} \leq 500 \\
& \frac{C}{t} \leq 50
\end{aligned}
$$

To ensure sufficient rigidity and to prevent buckling of the edge stiffener, the dimensions of the edge stiffener should be between the following values [15]:

$$
\begin{aligned}
& 45^{\circ} \leq \alpha \leq 135^{\circ} \\
& 0.2 \leq \frac{C}{b f} \leq 0.6
\end{aligned}
$$

Fig. 1 shows the theoretical formulation procedure of I-beams with a single web, Figs. 2 and 3 present corrugated webs (angular and trapezoidal). Fig. 4 shows a three-dimensional view of the beams tested and Tab. 1 summarizes all the dimensions based on Eurocode 3.

\begin{tabular}{ccccc}
\hline Parameter & Unit & Normal web & Trapezoidal web & Triangular web \\
Height of profile, $\mathrm{H}$ & $(\mathrm{mm})$ & 300 & 300 & 300 \\
Width of flange, bf & $(\mathrm{mm})$ & 150 & 150 & 150 \\
Tickness of flange, $\mathrm{tf}$ & $(\mathrm{mm})$ & 3 & 3 & 3 \\
Thickness of web, tw & $(\mathrm{mm})$ & 3 & 3 & 3 \\
Height of web, dw & $(\mathrm{mm})$ & 294 & 294 & 294 \\
Length of dropped edge, C & $\mathrm{m})$ & 30 & 30 & 30 \\
Length of beam, L & $(\mathrm{m})$ & 12 & 12 & 12 \\
Corrugation width, Cw & $(\mathrm{mm})$ & - & 50 & 50 \\
Corrugation depth, Ct & $(\mathrm{mm})$ & - & 35 & 25 \\
Orientation angle, $\Theta$ & $\left({ }^{\circ}\right)$ & - & 55 & 45 \\
\hline
\end{tabular}

Table 1: Symbol definitions and nominal cross-sectional dimensions for the specimens. 

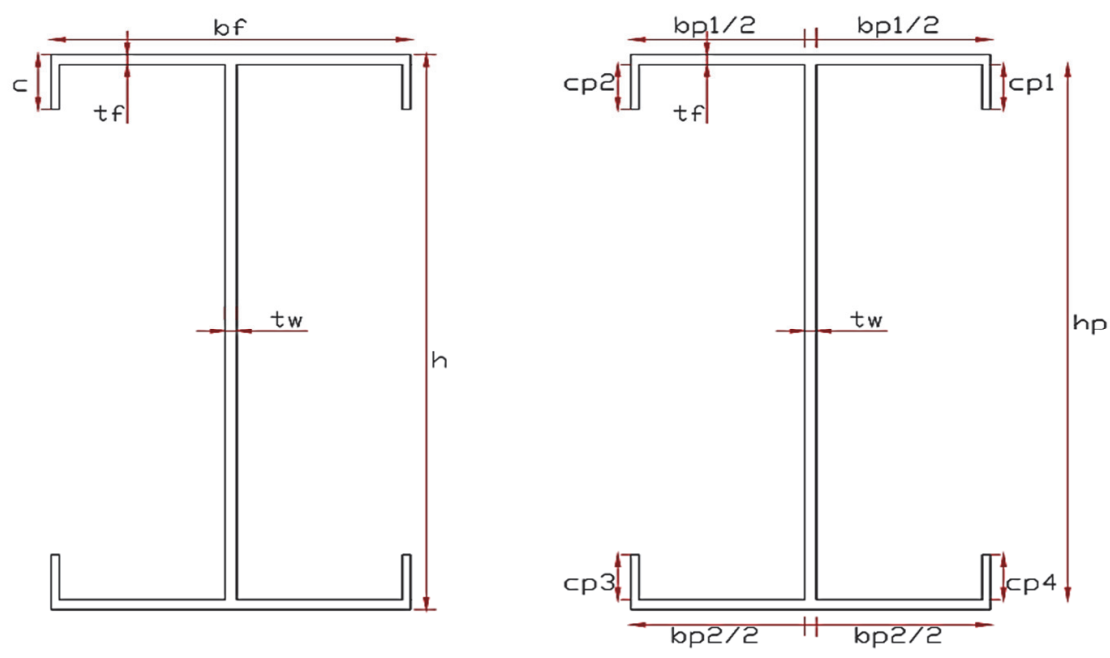

Figure 1: Design of I-beams with normal web.
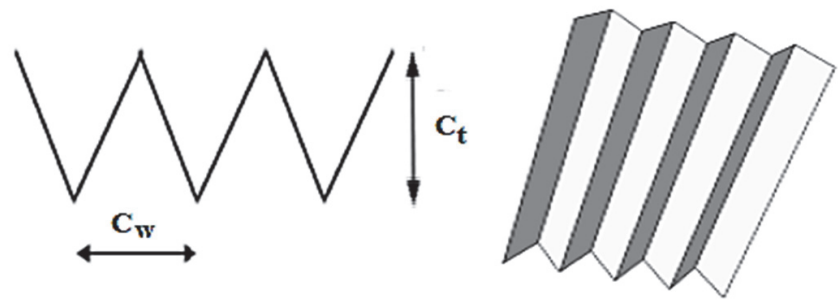

Figure 2: Triangular web.

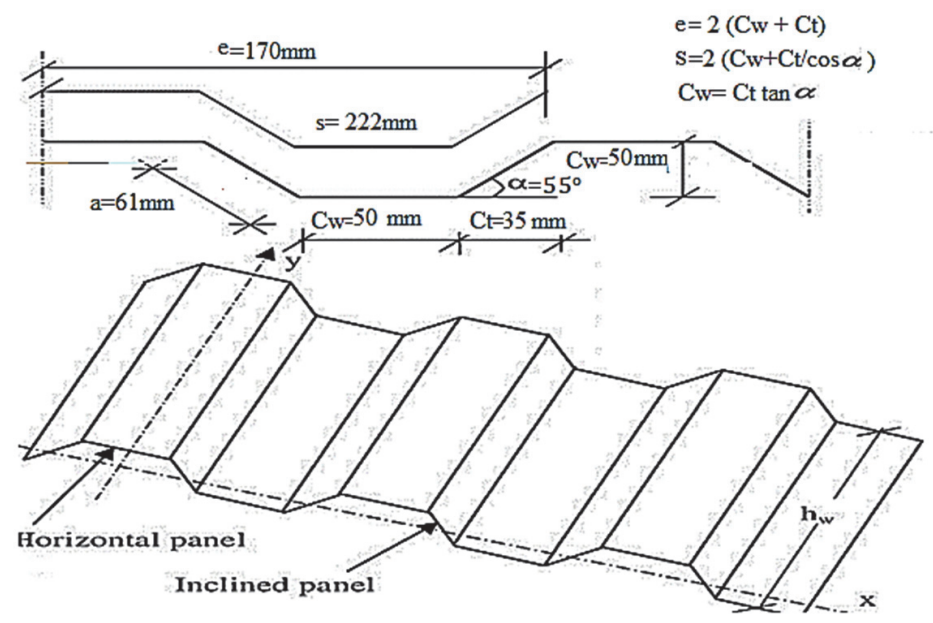

Figure 3: Trapezoidal web.

The cross sections of the profiles can be classified according to their ability to reach their limit state. This classification is influenced by the ability of sections to plasticize and the influence of instabilities. The Eurocode defines four types of classes. Gatheeshgar and al [13] describe the calculation of the effective properties of section I with flanged edges in the upper and lower flange in more detail. The properties of effective cross-sections in class 4 are based on the effective widths of the compression parts. To understand the phenomenon of instability of cold-formed elements, we have recourse to calculation codes, the most widely used, namely the European code (Eurocode), in the design philosophy of this type of profile is based on the principle of the effective width. This principle currently forms the basis of most of the calculation codes for cold-formed thin sections. 
CFS profiles are placed in class 4 because of their thicknesses and their susceptibility to local instability. In this class, the bending moment or compressive strength of a cross section must be determined with explicit consideration of the effects of local buckling [15] (Fig. 5).

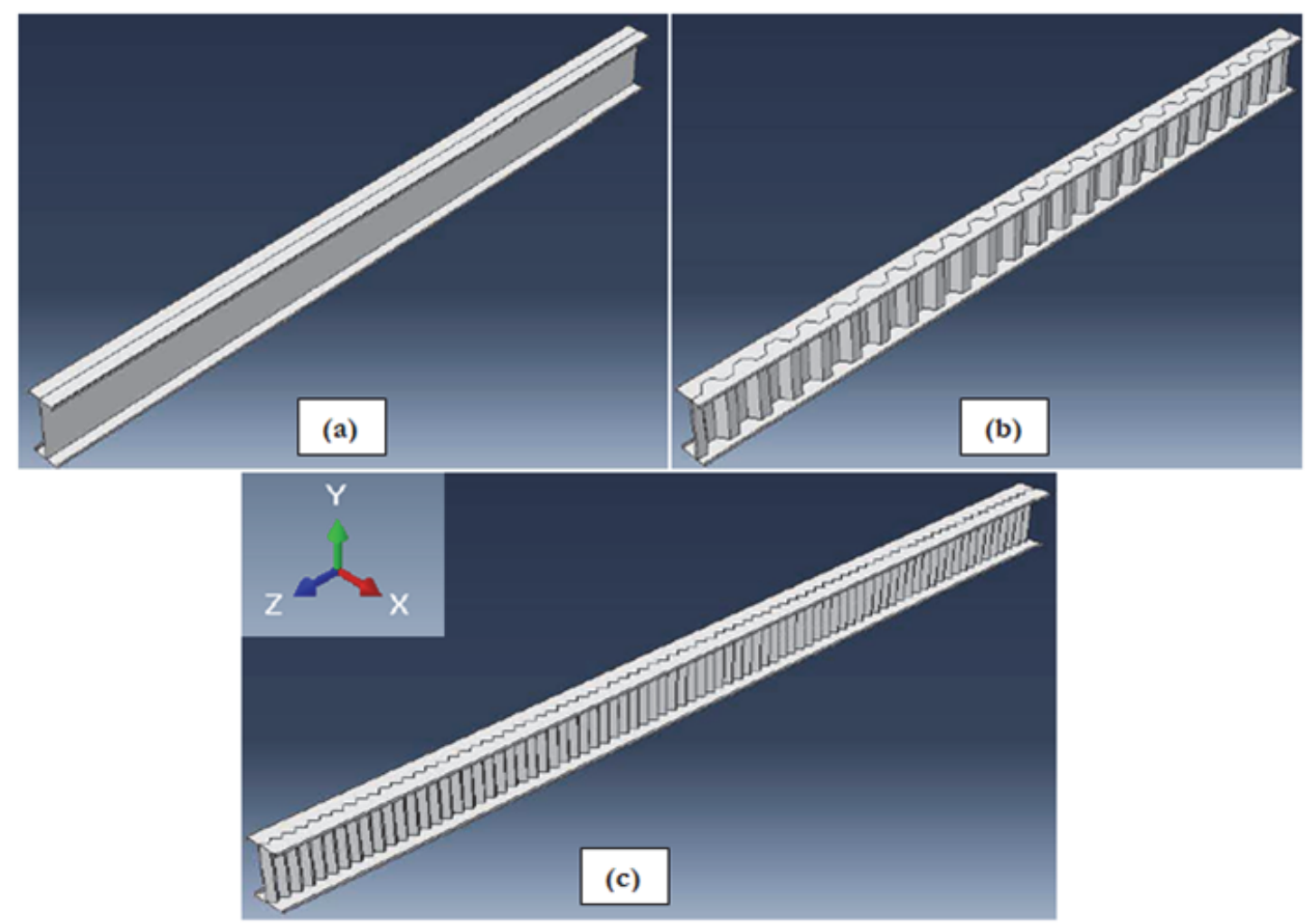

Figure 4: Three-dimensional view of beams with different webs: (a) Normal web; (b) Trapezoidal web; (c) Triangular web.

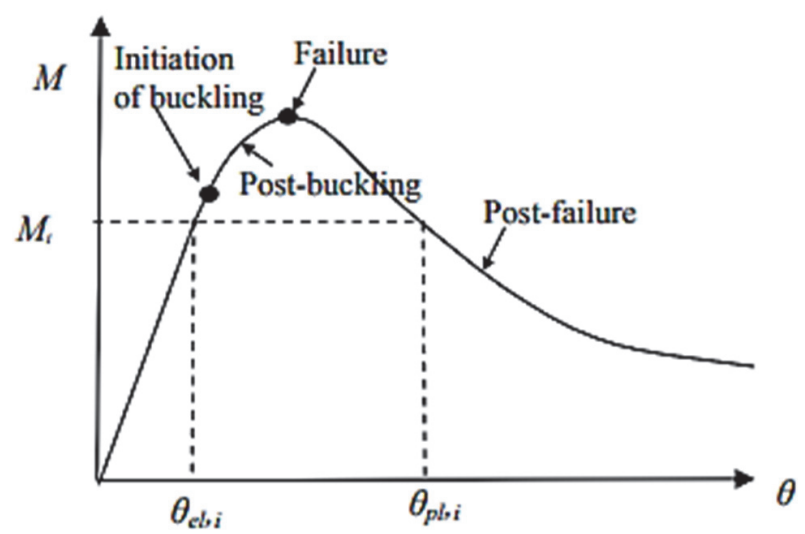

Figure 5: Diagram of moment-rotation curve of a single-span CFS beam [16].

The general iterative procedure should be applied to calculate the effective properties of the flange and the compressed edges (plane element with edge stiffener). The calculation is carried out in three steps:

The first step is to obtain an initial effective cross section for the stiffener using the effective widths of the flanges which are determined by considering that the compressed flanges are doubly supported as well as the stiffener provides full support $(K=\infty)$. The determination of the effective width of the compressed flanges takes into consideration the stress ratio: $\psi=1$ (uniform compression) and the buckling coefficient $k \sigma=4$. for an internal element in compression. The slenderness reduced for the upper and lower flange $\left(\lambda_{b p 1}, \lambda_{b p 2}\right)$ and the determination of the initial effective widths $b_{\text {eff } 1}, b_{\text {eff } 2}$ are based on the following formulas [15]: 


$$
\begin{aligned}
& \lambda_{b p 1,2}=\frac{\frac{b p 1}{t}}{28.4 \times \varepsilon \times \sqrt{k \sigma}} \\
& \varepsilon=\sqrt{\frac{235}{f y b\left(N / m^{2}\right)}} \\
& \rho_{1,2}=\frac{\lambda_{b p}-0.055(3+\psi)}{\lambda_{b p 1}^{2}} \\
& b_{e f 11,2}=\rho_{1} \times b_{p 1} \\
& b_{e 1,2}=0.5 \times b_{e f f 1,2} \\
& C_{e f f}=\rho \times C_{p}
\end{aligned}
$$

The second step is the use of the initial effective cross section to determine the reduction coefficient $\chi_{d}$, taking into account the effects of continuous elastic retention i.e the effective parts of the edge stiffener behave as a member fully supported by elastic springs of rigidity $\mathrm{K}$ along its central axis (Figs. $6 \mathrm{a}$ and $6 \mathrm{~b}$ ). The critical elastic buckling stress $\sigma_{c r, s}$ of the edge stiffener is

$$
\sigma_{\mathrm{cr}, \mathrm{s}}=\frac{2 \sqrt{\mathrm{KEIs}}}{\mathrm{As}}
$$

with: $\mathrm{K}$ is the stiffness of the elastic support per unit length. For the upper edge stiffener; Is is the effective moment of inertia and As is the effective area of the edge stiffeners. The thickness reduction coefficient $\chi_{d}$ for the edge stiffener is presented in Fig. 6c.

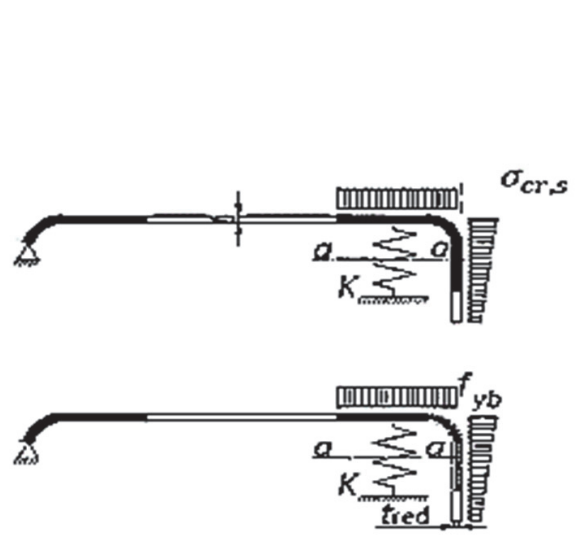

(a)

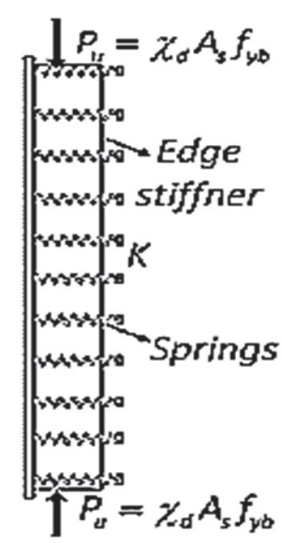

(b)

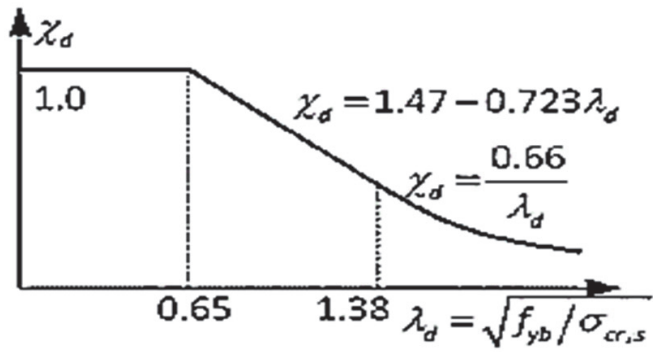

(c)

Figure 6: Distortional buckling model (a) flange with edge stiffener; (b) flexural buckling of edge stiffener as a strut on elastic foundation; and (c) flexural buckling [17].

The reduced slenderness $\lambda_{d}$ is given by the following formula [15,17]: 


$$
\begin{array}{ll}
\lambda_{d}=\sqrt{\frac{\mathrm{f}_{\mathrm{yb}}}{\sigma_{\mathrm{cr}, \mathrm{s}}}} & \\
\chi_{d}=1 & \text { if } \quad \lambda_{d} \leq 0.65 \\
\chi_{d}=1.47-0.723 \lambda_{d} & \text { if } \quad 0.65<\lambda_{d}<1.38 \\
\chi_{d}=\frac{0.66}{\lambda_{d}} & \text { if } 1.38 \leq \lambda_{d}
\end{array}
$$

In the last step, we can determine the area of the effective cross section (Fig. 7) and the effective inertia and modulus of resistance of the effective section: we repeat the first step by calculating the effective width with the reduced compressive stress $\sigma_{c r, s}$. The iteration is optional in Eurocode 3 with [17]:

$$
\chi_{d, n-1} \approx \chi_{d, n}
$$

But

$$
\begin{aligned}
& \chi_{d, n} \leq \chi_{d, n-1} \\
& \sigma_{c r, s}=\chi_{d} \frac{f_{y b}}{\gamma_{M 1}}
\end{aligned}
$$

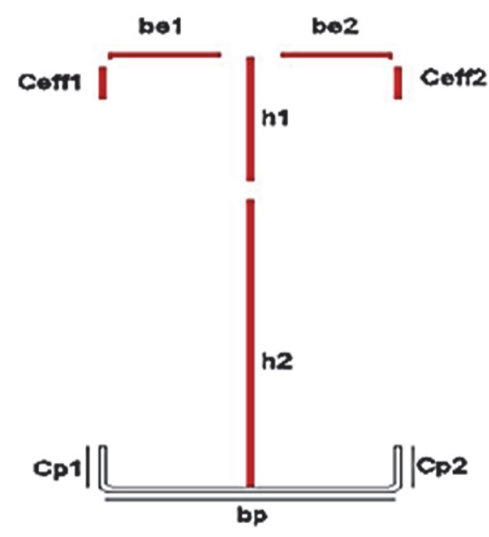

Figure 7: Different effective widths of each wall constituting the gross section I; The effective section (with red color); $C_{\text {eff } 1}, C_{e f f}$,

$L_{e 1}, L_{e 2}, h_{1}$ and $b_{2}$ are the effective widths $C_{p 3}, C_{p 4}$ and $b_{p 2}$ are the non-effective areas.

\section{Bending check}

In a single span simple beam, failure occurs when the value of the bending moment (Msd) exceeds the resistance moment of the cross section, the magnitude of which depends on the shape of the profile, the strength of the material, and the classification of the section. In cases where the shear force exerted on the cross-section can be considered small enough that its effect on the design resistance moment can be neglected (EC3 sets a shear force value of $50 \%$ of the plastic design resistance to shear). the bending resistance of the cross-section must satisfy the following conditions [15]: 


\section{The resistance:}

$$
\frac{\mathrm{M}_{\mathrm{ed}}}{\mathrm{M}_{\mathrm{c}, \mathrm{Rd}}} \leq 1
$$

with:

$\mathrm{M}_{\mathrm{C}, \mathrm{Rd}}$ is the design value of the bending resistance with respect to a principal axis of the section; $\mathrm{M}_{\mathrm{ed}}$ is the bending moment at the ultimate limit state [15].

$$
\begin{aligned}
& \mathrm{M}_{\mathrm{C}, \mathrm{Rd}}=\frac{\mathrm{W}_{\text {eff }, \mathrm{y}} \times \mathrm{f}_{\mathrm{yb}}}{\gamma_{\mathrm{M} 0}} \\
& \mathrm{~W}_{\text {eff, } \mathrm{y}}=\frac{\mathrm{I}_{\text {eff }}}{\mathrm{Z}_{\mathrm{c}}}
\end{aligned}
$$

Shearing effort:

The plastic shear strength $\mathrm{V}_{\text {pl.Rd }}$ shall be determined by [15]:

$$
V_{s d} \leq V_{p l . R d}=\frac{h_{w}}{\sin \phi} t \frac{\frac{f_{y}}{\sqrt{3}}}{\gamma_{M 0}} .
$$

with:

$V_{p l . R d}:$ Design value of the plastic shear strength.

$\phi$ : Inclination angle of the web relative to the flanges.

Displacement condition:

Specify for concentrated load in the middle is three point bending [15].

$$
f_{\max }=\frac{\mathrm{P} \times(\text { Span })^{3}}{48 \mathrm{E} \mathrm{I}_{\mathrm{y}}} \leq f_{\text {adm }}=\frac{\text { Spain }}{200}
$$

Regarding Eurocode 3, the hot-rolled sections calculation procedure is used for cold-formed sections, except that this requires the determination of the effective section, which is not easy. To enhance the analytical results, the numerical study has been performed.

\section{FINITE ELEMENT MODELING}

1 he finite element method is a numerical analysis technique for obtaining approximate solutions to a wide variety of engineering problems. The basic concept of finite element analysis is that a structure is divided into a finite number of elements having finite dimensions and reducing the structure having infinite degrees of freedom to finite degrees of freedom [18].

For finite element analysis, the advanced ABAQUS software was used for our numerical simulation [2,19-22]. The goal of our project is the design of beam models on two supports subjected to bending. The models studied are I-beams with a span of $12 \mathrm{~m}$ in cold formed steel with different web sections ie. be a solid core and a corrugated core (trapezoidal or triangular) $3 \mathrm{~mm}$ thick. The ripple angle for the trapezoidal model is $55^{\circ}$ and $45^{\circ}$ in the triangular model as shown in Tab. 1. The cross sections of the three beams are $150 \times 300 \times 3 \mathrm{~mm}^{3}$. The beams were stressed by a concentrated load in the 
middle (three-point bending) with increasing static loading in order to develop a more efficient element. The beams are considered to be made of high yield strength steel for cold forming (S355 according to EN10149-2).

During the production process of cold formed elements, the initial mechanical properties of steel are often changed. The shaping operation is usually accompanied by an increase in the elastic limit $f_{y b}$ and the tensile strength $f_{u}$. Tab. 2 summarizes the mechanical properties of the beam with a single web and the beams with corrugated webs (triangular and trapezoidal).

When the forming force is applied to the sheet, the sheet will deform and plasticize to the desired shape reaching certain stress. It will represent the new elastic limit if we recharge immediately. On the other hand, if we recharge after a certain time, the elastic limit will be more important [23]. In reality, the increase in tensile strength fu is much smaller than that in elastic limit $f_{y b}$ so the shape of the stress-strain curve of the steel will change and be like that shown in Fig. 8. In this case, the elastic limit $f_{y}$ is determined for a strain equal to 0.002 , Young's modulus, Poisson's ratio are $2.1 \times 10^{5}$. MPa and 0.3 respectively. In the numerical model, the manufacturing process is considered taking into account the mechanical properties of materials determined after the production process due to residual stresses.

\begin{tabular}{|c|c|c|c|c|c|}
\hline Element & $\begin{array}{l}\text { Density } \\
\Upsilon \\
\left(\mathrm{kg} / \mathrm{m}^{3}\right)\end{array}$ & $\begin{array}{c}\text { Young's modulus } \\
\mathrm{E} \\
(\mathrm{MPa})\end{array}$ & $\begin{array}{c}\text { Poisson Coefficient } \\
\vartheta\end{array}$ & $\begin{array}{l}\text { Elastic limit } \\
\qquad f_{y b} \\
(\mathrm{MPa})\end{array}$ & $\begin{array}{c}\text { Tensile strength } \\
f_{u} . \\
(\mathrm{MPa})\end{array}$ \\
\hline $\begin{array}{l}\text { Beam with normal web } \\
\text { Beam with Trapezoidal web } \\
\text { Beam with Triangular web }\end{array}$ & 7850 & 210000 & 0.3 & 355 & 430 \\
\hline
\end{tabular}

Table 2: Mechanical properties of the beam's steel studied.

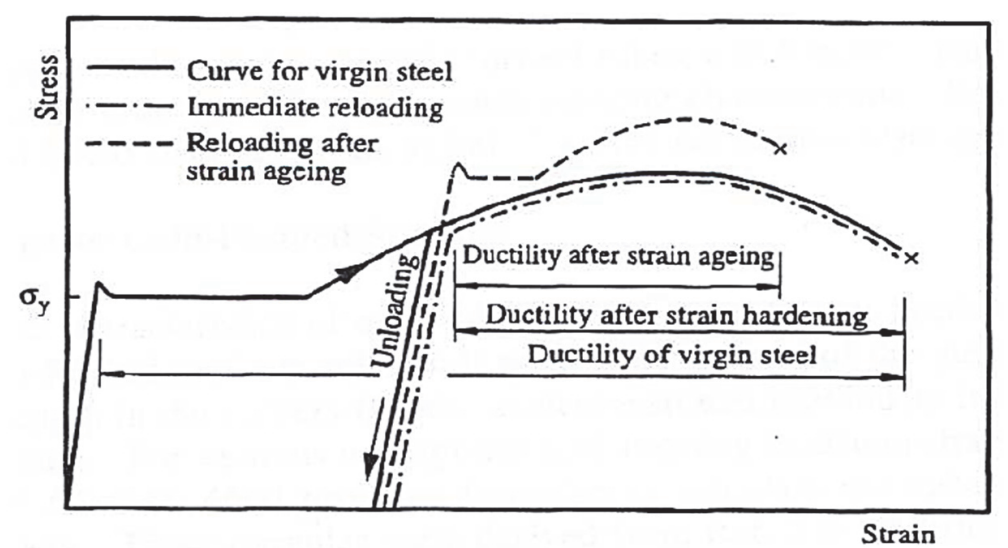

Figure 8: Effect of strain hardening and strain aging on stress - strain characteristics [23].

\section{Geometry and mesh}

The mesh used represents a good compromise between the calculation time and the precision of the results. For the nonlinear mechanical analysis, the beams are modeled as plate elements assembled together, then for the mesh, it refers to the library of ABAQUS and according to a case study proposed by it. In our study; elements of the S8R type are used, including S8R: A thick shell with 8 nodes doubly curved, reduced integration. This brick element can be used effectively in geometric and material nonlinear analysis which have been taken into account, including plasticity, contact, large displacements, and fracture. An example of finite element mesh of modeled beams is presented in Fig. 9.

\section{Loading and boundary conditions}

The tested beams are simply supported, the boundary conditions result in a blocking of displacements at the level of the first support where one has $\left(U_{x}=U_{y}=U_{z}=0\right)$. On the other hand, the other support there is a blocking of displacements and rotation which ensures $\left(U_{x}=U_{y}=R_{x}=0\right)$ (Fig. 10). The model taken is that respecting an isostatic beam where the model symmetry has not been exploited. The external loading is bending and presented by a concentrated load applied to 
the middle of the upper flange (three-point bending) and increasing in intensity, which varies up to the load $P=10 \mathrm{kN}$ (Fig. 11). The case taken is that of the applied charge seen that our case is a main element of resistance.
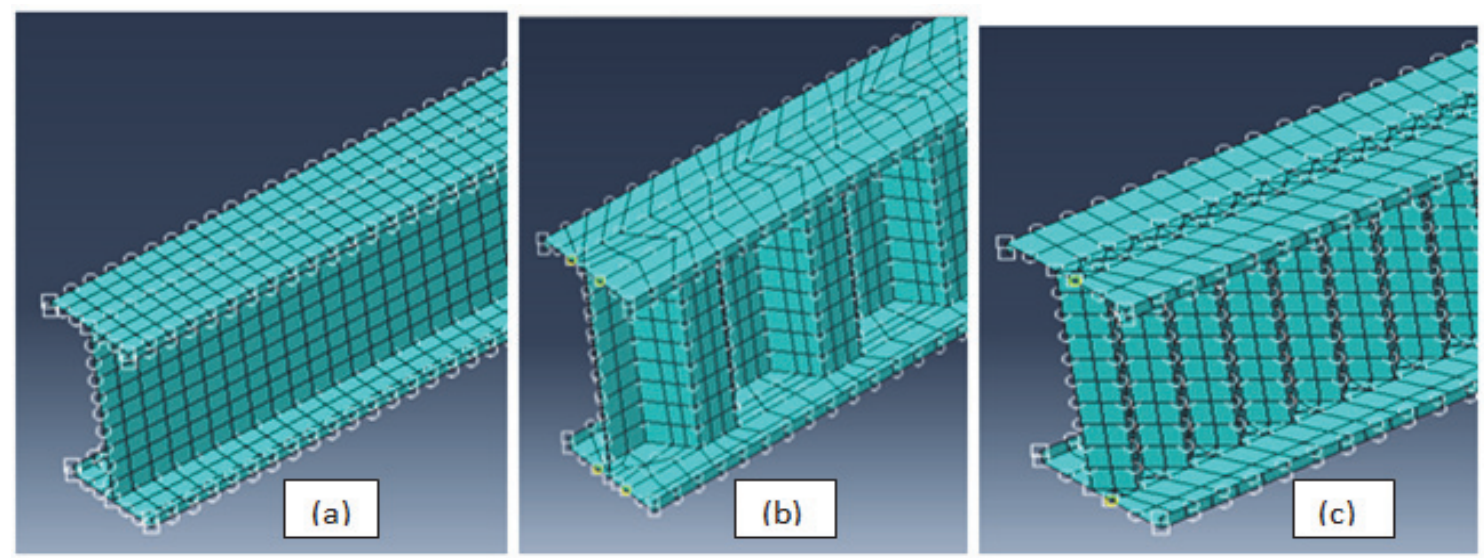

Figure 9: Finite element meshing of models: (a) Normal web; (b) Trapezoidal web; (c) Triangular Trapezoidal web.

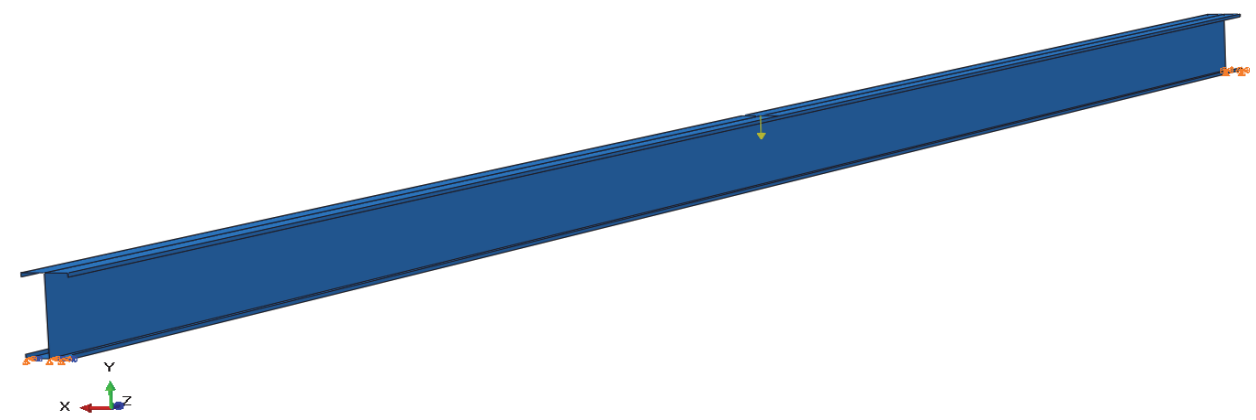

(a)

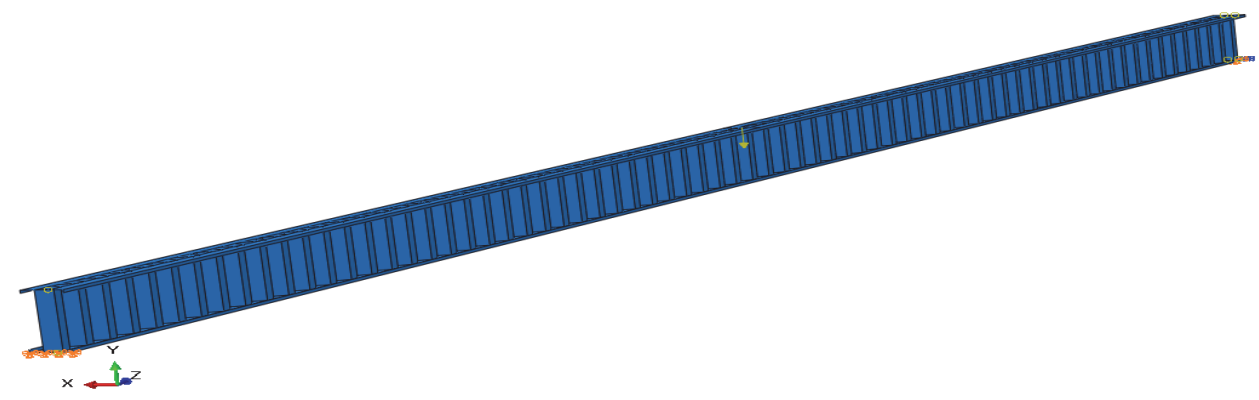

(b)

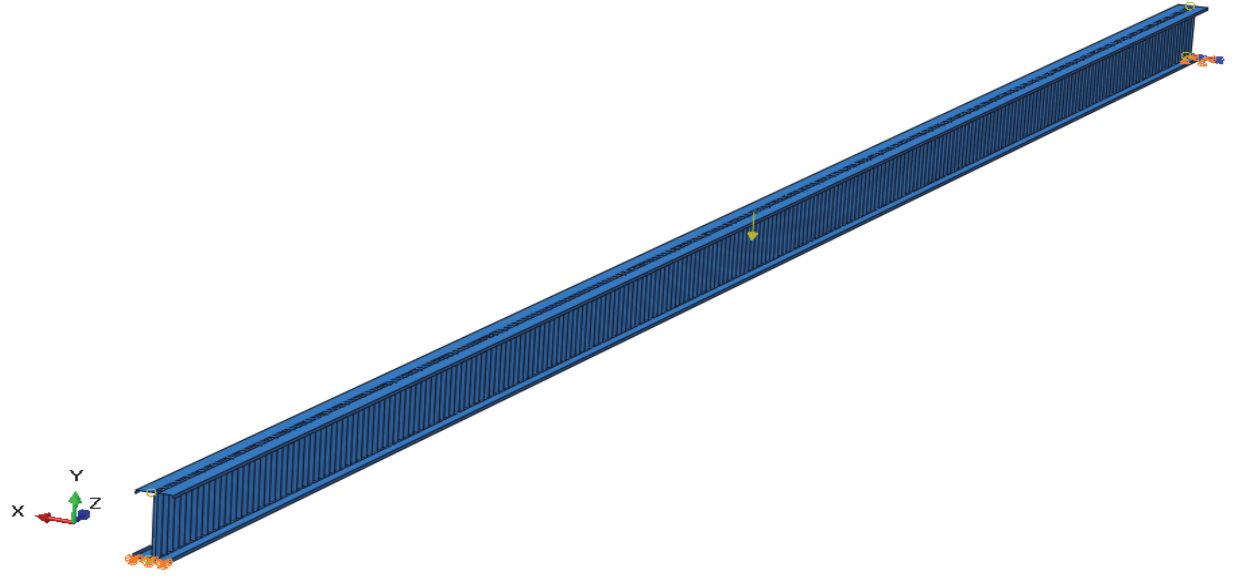

(c)

Figure 10: Boundary condition for the beams studied: (a) Normal web; (b) Trapezoidal web; (c) Triangular Trapezoidal web. 


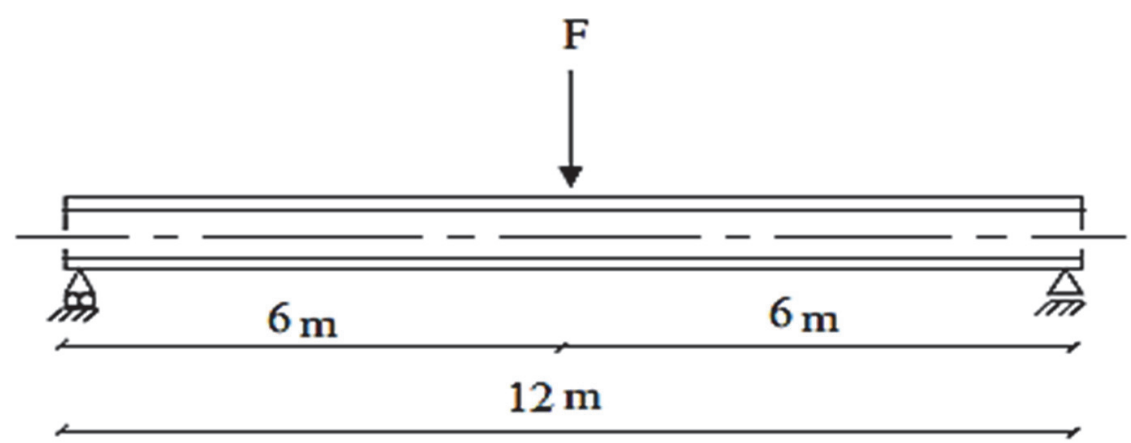

Figure 11: The loading adopted for the tested beams.

\section{RESULTS AND DISCUSSION}

$\mathrm{C}$ orrugated web beams are advantageous for the construction industry, due to the maximum lateral stiffness. The main objective of this study is to analyze the behavior of beams with corrugated webs (trapezoidal or triangular) and a flat web, by an analytical approach and a theoretical approach. It is shown that for a load of $6 \mathrm{kN}$, the corrugated web beams (trapezoidal and triangular) exhibited a decrease in displacement $U_{y}$ of around 36\% and 17\% respectively, compared to the single web beam. Besides the beam I shows a concentration of displacements in the area of application of the load with $U_{\max }=105 \mathrm{~mm}$ (central area) as shown in Fig. 12a.

The triangular web beam presented a significant lateral displacement compared to the other beams (simple and trapezoidal), this lateral displacement results in instability. On the other hand, we notice a reduction in displacement $U_{x}$. of about $21 \%$ for the beam model with trapezoidal web, compared with the solid web beam. The beam with a trapezoidal corrugated web has a maximum load capacity compared to the smooth web [13]. A cold formed steel beam with a corrugated web has a lower deflection than steel beams with a smooth web [18] (Fig. 12b).
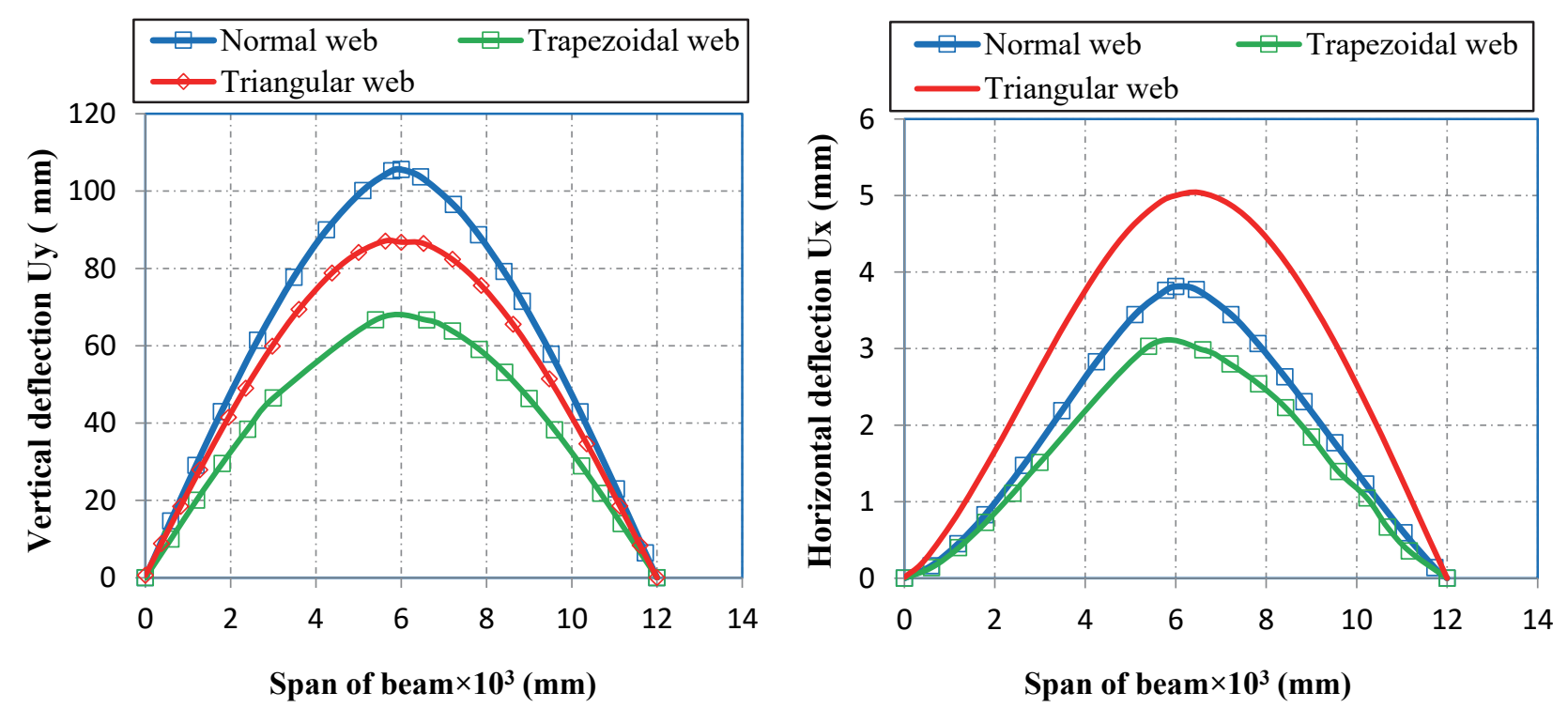

Figure 12: State of vertical $\left(U_{y}\right)$ and horizontal $\left(U_{x}\right)$ displacement according to the span of the tested beams.

For a load of $6 \mathrm{kN}$, it can be seen that the trapezoidal corrugated web beam and the I-beam presented a very remarkable rigidity from a deformation reduction point of view. A $15 \%$ reduction in deformation compared to the normal web beam. The central area is the most stressed (the area of load application) as shown in Fig. 13. This type of deformation is of 
importance for long beams with low lateral and torsional stiffness. Similar behavior from a deformation point of view for the simple model and the triangular model. A coincidence of curves except for the load application area has been observed.

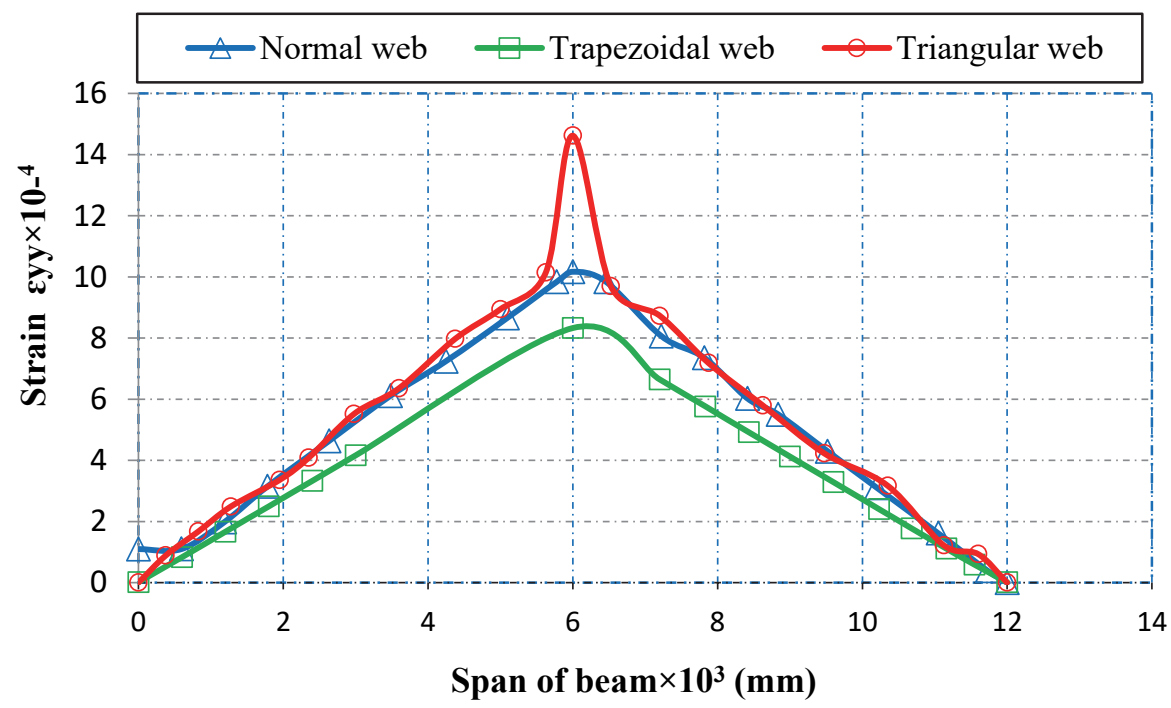

Figure 13: State of deformation according to the length of the studied beams.

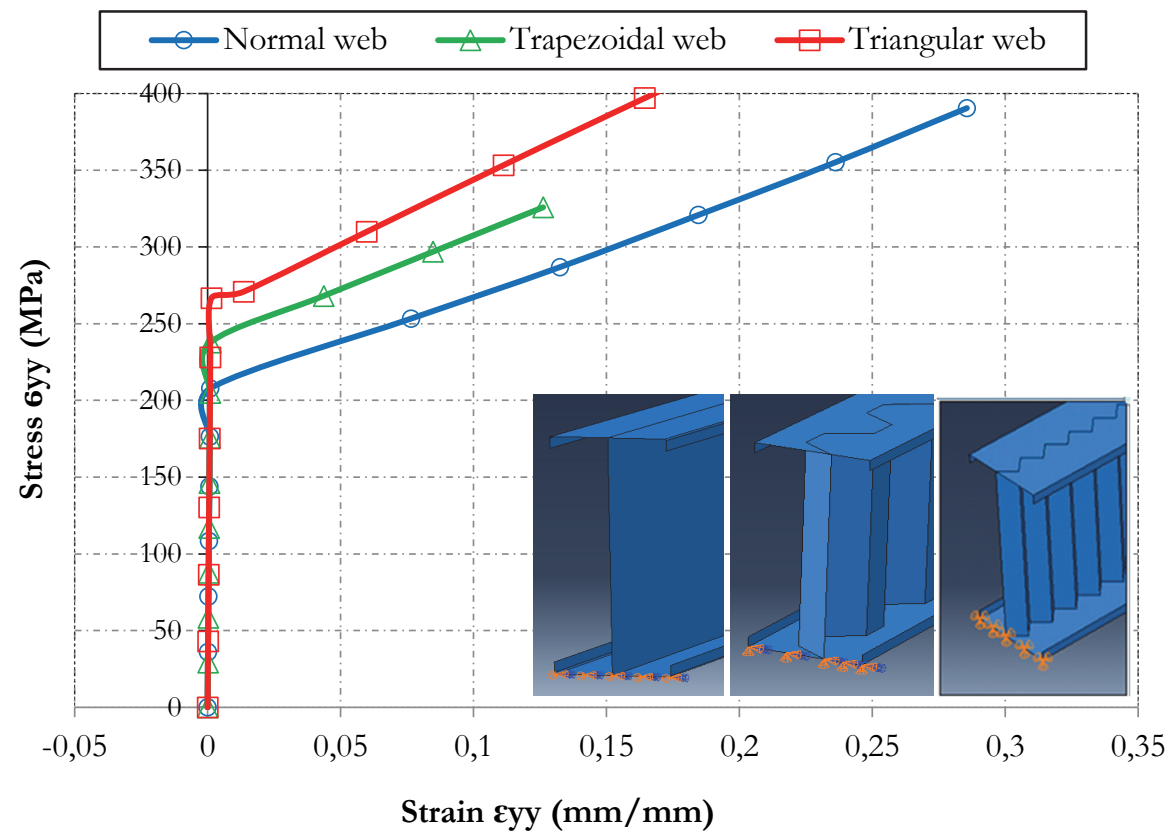

Figure 14: Comparative stress-deformation state of tessellated beams.

For the different beams studied, we measured the state of stress deformation in the center point of the lower flange. By describing the constitutive law of the three studied beams, the three models have a nonlinear behavior. In the linear mode, at the beginning of the loading, the beams presented an elastic behavior whose strains are proportional to the applied forces $\left(\varepsilon_{\text {elas }}=2 \%\right.$ o . Plasticization of the material is obtained for higher values. Plasticity results in the dissipation of energy during deformation, mechanical energy is transformed and leading to the irreversibility of the behavior of the material, this mechanism also reflects the ductility of the material, which allows the beam to undergo elongation significant before breaking up as shown in fig. 14. All three beams get plasticized before the elastic limit ( $355 \mathrm{MPa})$ is reached, confirming the theory of efficient section and class 4 [15]. The single-core model exhibited large deformations. Failure occurs in the cold formed solid core beam by distortional lateral buckling and local buckling. The triangular core beam showed an increase in 
yield strength compared to other models. The stress concentration occurs near the center point. Failure of the corrugated beam is accomplished by lateral torsional buckling.

Fig. 15 shows the state (load - horizontal displacement Ux) in the center point of the lower flange and it was found In the range of 0 to $7 \mathrm{kN}$, the beams with wavy (triangular and trapezoidal) have shown small displacement which translates into a remarkable linearity. Above $7 \mathrm{kN}$, the beam with a trapezoidal web core has a lower lateral displacement of the order of $44 \%$ compared to the beam with a single web. Models (beam with single and triangular webs) have a risk of torsional lateral buckling [12]. The triangular soul beam undergoes significant lateral displacement compared to other beams.

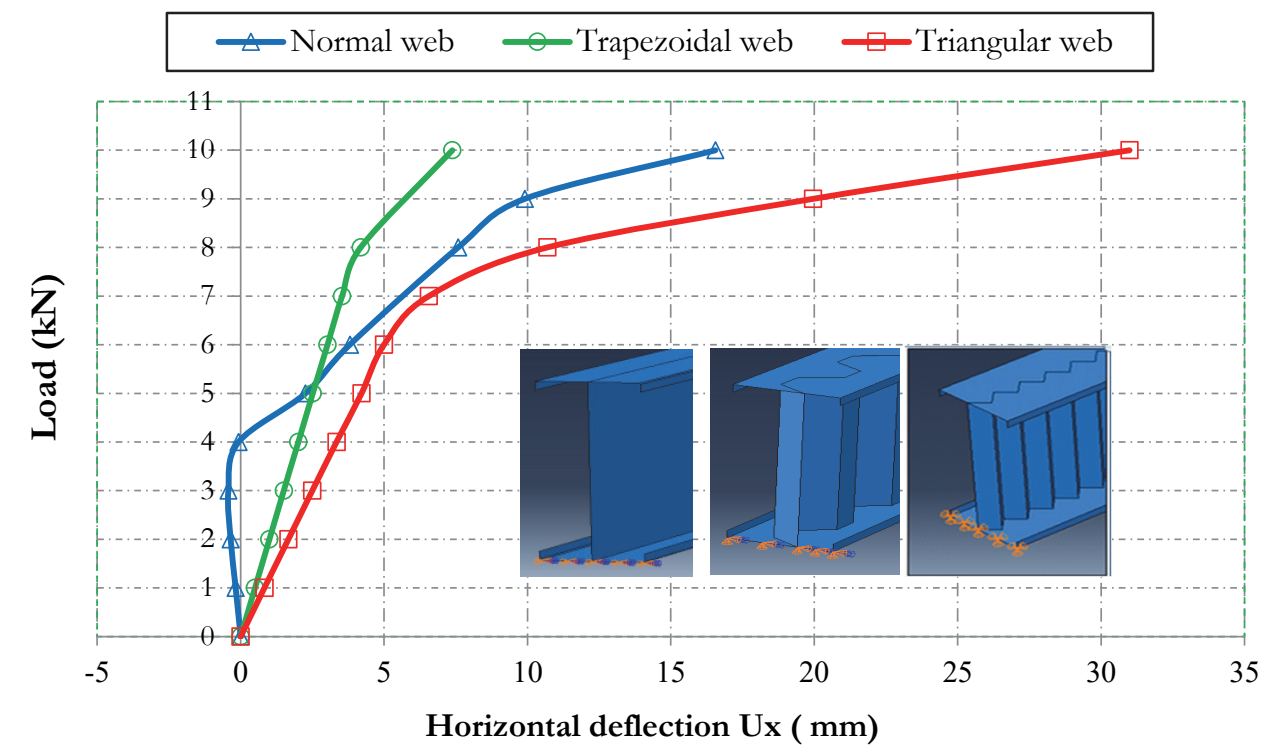

Figure 15: Comparative state (load-deflection Ux) of the studied beams.

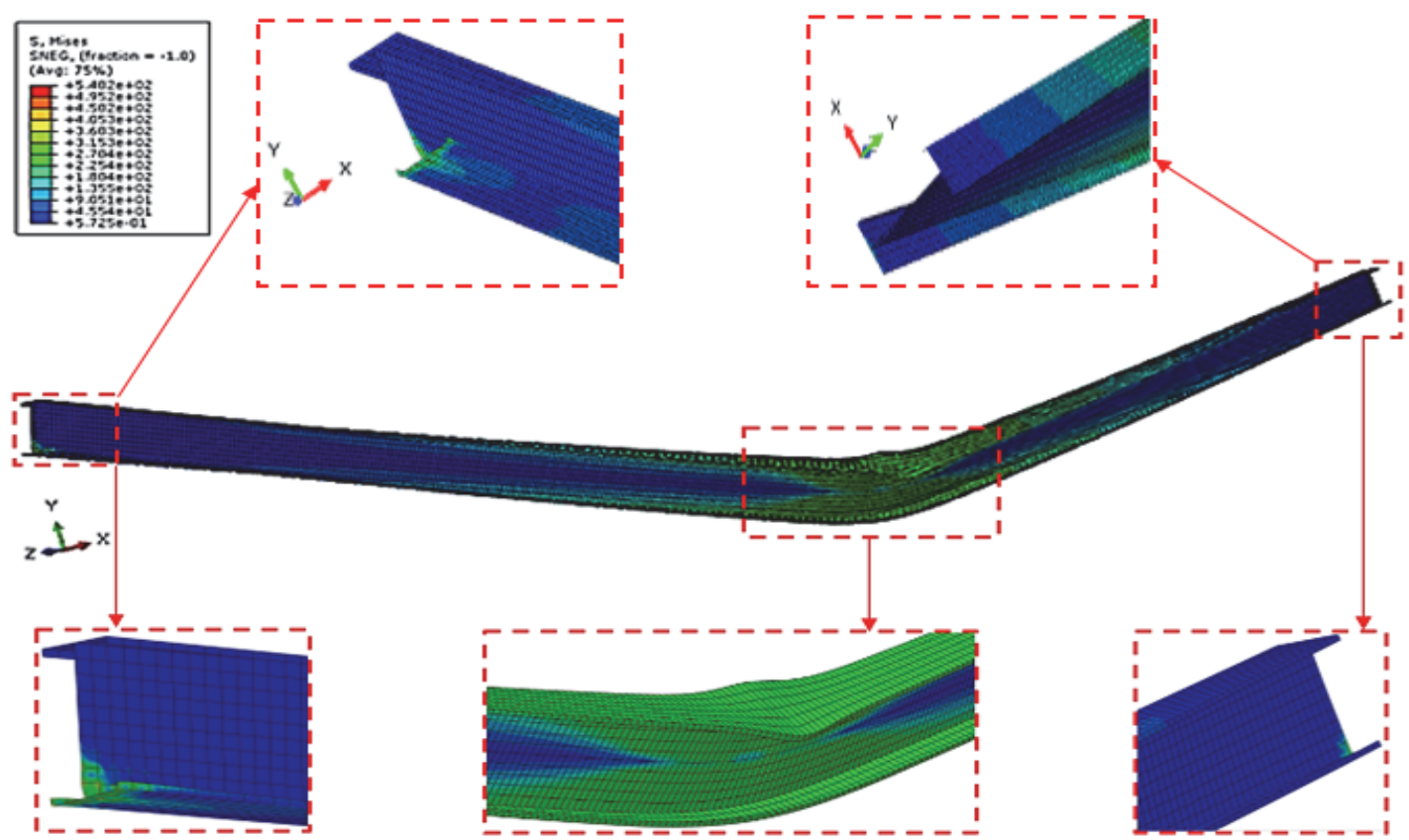

Figure 16: Failure mode (Mises stress state) of beams with normal webs.

Fig. 16 shows the failure mode of the single web beam modeled with the ABAQUS software which was chosen because of its high performance and precision [19-22,24]. It is noted that the beam I has undergone a local buckling in the upper flange at the level of the zone of application of the load in addition to a distortional lateral buckling. This last mode occurs because 
the beam is slender and is characterized by the fibre, which moves laterally, and the transverse load exerts torsion (low lateral stiffness and low torsional stiffness).

The excessive compression in the compressed part of the beam causes this part to buckle, which causes it to come out of its main plane of bending while the tensioned part remains in its plane.

It is observed that the ripple angle increases when the load capacity increases (Fig. 15). The rupture of the core is eliminated thanks to the presence of corrugations in the core [25]. The trapezoidal corrugated blade has better stiffness in bending and shearing out of the plane [26].

Fig. 17 presents the failure mode of the beam with the trapezoidal web. It showed local buckling in the load application area. The beam is subjected to compressive forces, which is why it tends to be veiled locally. This mode only involves the out-of-plane flexion of the top sole without deformation of the flanged junction lines, that is to say just one rotation and no deformation (Fig. 17). It is shown from the rupture mode that the lateral buckling resistance of the web increases with the trapezoidal corrugation web. The results are in the same trend as those of Divahar and Joanna [26].

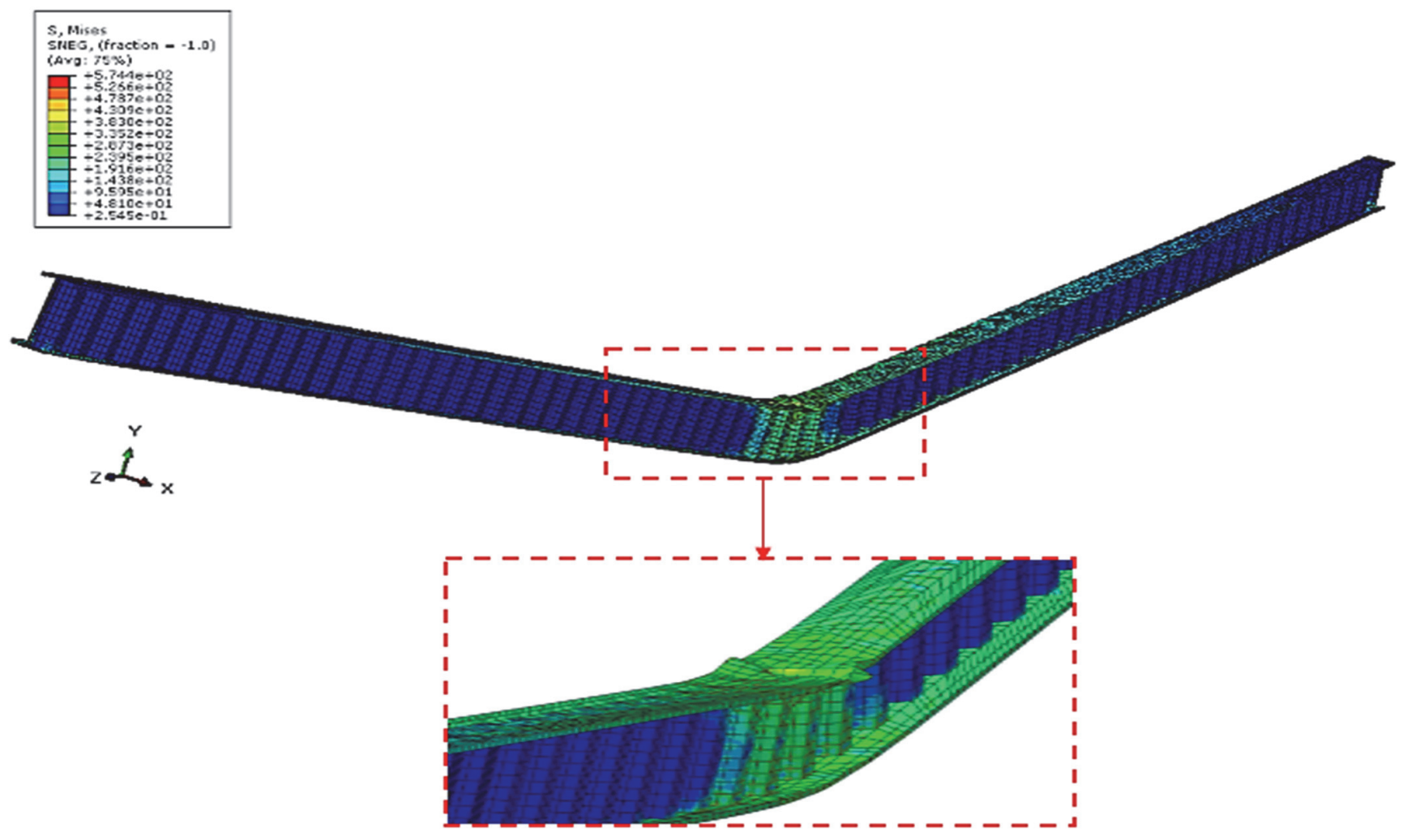

Figure 17: Failure mode (Mises stress state) of beam with corrugated web: beam with trapezoidal web.

Fig. 18 presents the failure mode of the beam with the triangular web. The triangular core beam breaks by lateral torsional deformation due to the large gap in the web section, this finding has the same tendency as those of Preethi et al [12].

The stress concentration occurs near the center point. Failure of the corrugated beam is accomplished by torsional lateral buckling (Fig. 18).

From the point of view (load - vertical displacement $\mathrm{Uy}$ ) at the level of the central point of the lower flange, during the increase of the applied load, it is noted that the beams with corrugated webs (trapezoidal and triangular) presented a maximum capacity i.e for a load of $7 \mathrm{kN}$, a reduction of displacement of order $84 \%$ and $31 \%$ for the model with trapezoidal and triangular undulation respectively compared to the model of the simple beam (Fig. 19).

The results of the numerical study are shown in Tab. 3, which shows the maximum deflections, maximum stresses, major moments, and the ultimate failure mode of beams with a single web and a corrugated web [18]. 

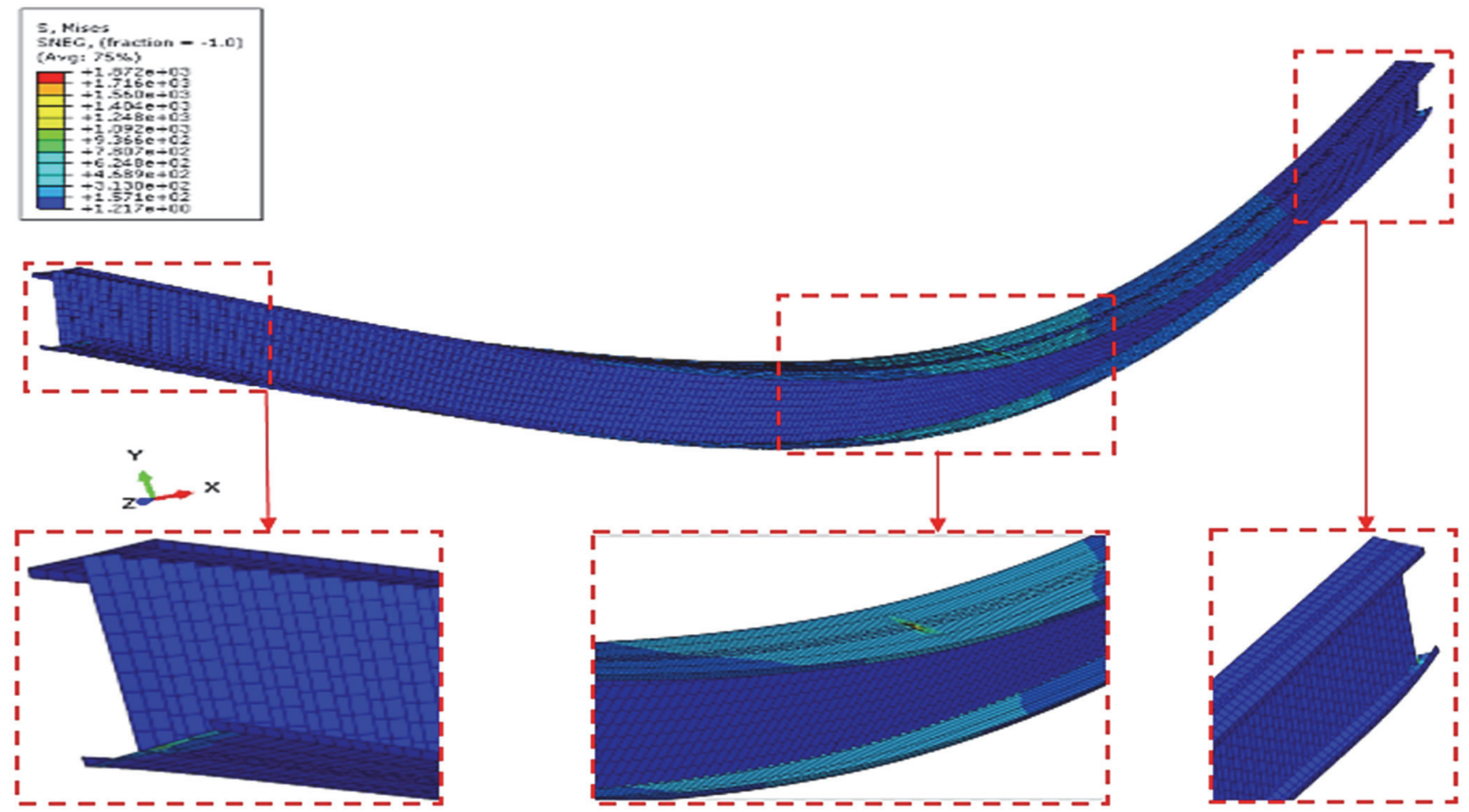

Figure 18: Failure mode (Mises stress state) of beam with corrugated web: beam with triangular web.

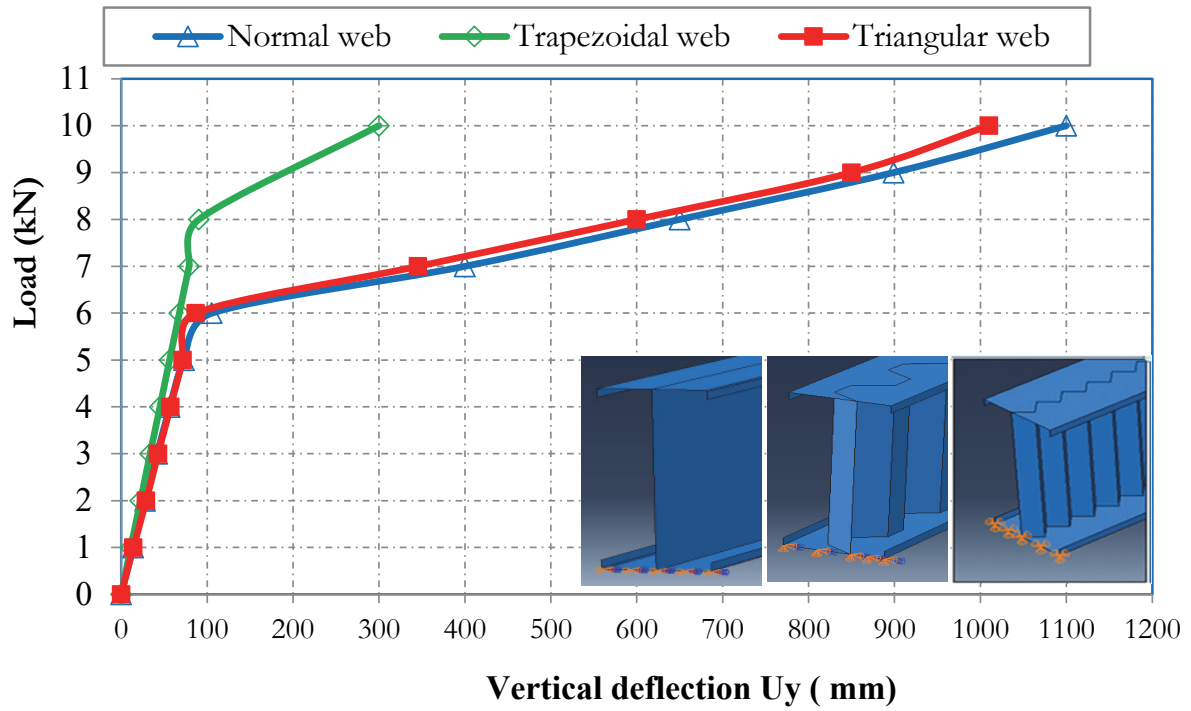

Figure 19: Comparative state (load-deflection Uy) of the studied beams.

\begin{tabular}{|c|c|c|c|c|c|}
\hline Element & $\begin{array}{c}\text { Horizontal } \\
\text { deflection } \\
U_{x} \\
(\mathrm{~mm})\end{array}$ & $\begin{array}{c}\text { Vertical } \\
\text { deflection } \\
U_{y} \\
(\mathrm{~mm})\end{array}$ & $\begin{array}{c}\text { Stress } \\
\sigma_{y y} . \\
(\mathrm{MPa})\end{array}$ & $\begin{array}{c}\text { Moment } \\
\text { analytical } \\
\text { M } \\
(\mathrm{kN} . \mathrm{m})\end{array}$ & Failure mode \\
\hline Beam with normal web & 3.81 & 105.54 & 207.85 & 49.28 & $\begin{array}{c}\text { Local and lateral torsional } \\
\text { buckling }\end{array}$ \\
\hline Beam with Trapezoidal web & 3.02 & 86.78 & 175.43 & 39.69 & Local buckling \\
\hline Beam with Triangular web & 5.00 & 67.67 & 266.57 & 64.23 & Lateral torsional buckling \\
\hline
\end{tabular}

Table 3: Numerical results for flexural capacity. 


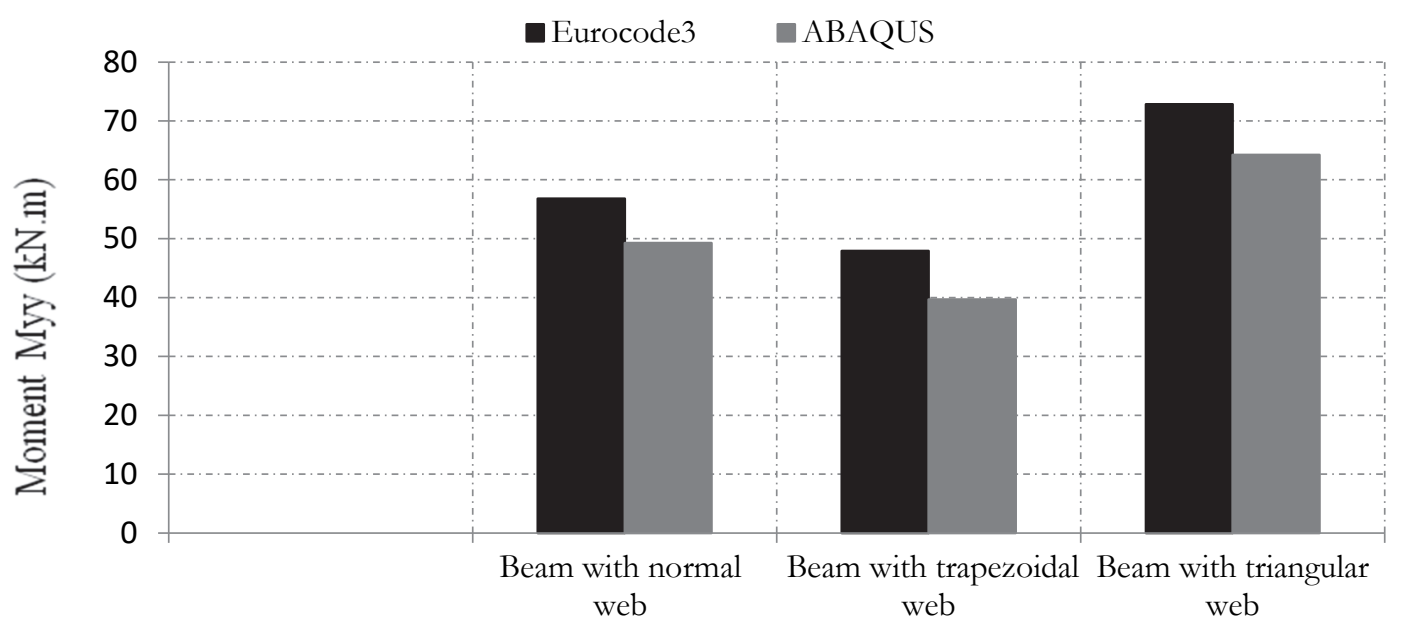

Figure 18: Comparison of beams moment state according to ABAQUS and Eurocode 3.

For a load of 6 kN, Fig. 18 shows a very good correlation between numerical results and those proposed by Eurocode 3 part 1-3, a difference less than 13\%. The numerical results confirm that the triangular corrugated web beam has a maximum moment capacity compared to all models, which is $25 \%$ higher than the ordinary web. The trapezoidal core configuration has greater strength compared to the triangular and ordinary core configuration.

Eurocode 3 gives a more unfavorable state of moment compared to other models because Eurocode is based on experimentation, which is why some failures can be found. Therefore, the corrugated steel beam is economical in all respects [27]. The beam whose web is trapezoidal corrugated has greater moment resistance and greater rigidity compared to the single-web beam. This displacement ductility can influence the increase in stiffness of the corrugated web [26].

\section{CONCLUSIONS}

7 he numerical study and the theoretical approach on section I beams with different web shapes allowed us to draw the following conclusions:

- Tried metal beams are made of relatively thin parts and with significant slenderness. They are particularly sensitive to the phenomena of instability. The single web beam exhibited a significant lateral displacement compared to the corrugated web beams (triangular and trapezoidal) and a local buckling, this lateral displacement results in instability i.e a distortional lateral buckling.

- The beam with trapezoidal web showed a failure in the upper flange of the central zone which is defined by local buckling.

- The beam with the triangular web exhibited a significant torsional lateral displacement in the central zone.

- Analysis shows that an I-beam with a corrugated web will twist out of the plane at the same time as it deforms in the plane under the action of loads in the plane.

- By increasing the load, and in the midpoint of the bottom flange. It can be seen that the beams with corrugated webs (trapezoidal and triangular) showed a reduction in displacement $U_{y}$ of the order of $84 \%$ and $31 \%$ respectively.

- The trapezoidal corrugated web presented a maximum capacity compared to the beam model with regular and triangular web:

- A decrease of $21 \%$ in $U_{x}$ displacement point of view.

- A $36 \%$ decrease in $U_{y}$ displacement point of view.

- Corrugated web beams are advantageous for the construction industry due to their maximum lateral stiffness.

- Corrugation improves the bending capacity and the beam stiffness, especially for trapezoidal web beams.

- The load capacity is higher for beams with corrugated webs compared to beams with a normal web.

- The European Eurocode 3 regulation is effective for dedicating to the sizing and design of thin cold formed beams. 


\section{NOMENCLATURE}

CFS: Cold-formed steel.

$\mathrm{h}:$ Height of profile.

$b_{f}:$ Width of flange.

$t_{f}$ : Thickness of flange.

$t_{w}$ : Thickness of web.

$d_{w}:$ Height of web.

C: Length of dropped edge.

$\mathrm{t}:$ Section thickness.

$h_{p}:$ Height of web.

$b_{p 1}, b_{p 2}:$ Initial effective widths.

$b_{p 1} / 2, b_{p 2} / 2:$ Half initial effective widths.

$C_{p 1}, C_{p 2}, C_{p 3}, C_{p 4}:$ Initial effective width of flanged edges.

$l_{e 1}, l_{e 2}$ : Effective sole widths.

$C_{e f f 1}$ : Effective width of flanged edges.

$h_{1}, h_{2}$ : Effective initial height of the web.

L: Length of beam.

$C_{w}$ : Corrugation width

$C_{t}$ : Corrugation depth

$\theta$ : Orientation angle.: The yield strength of steel.

$f_{u}$ : Ultimate strength.

E: Elasticity module.

७: Poisson coefficient

$\gamma_{M 0}$ : Partial factor for resistance of cross-sections.

$\gamma_{M 1}$ : Partial factor for resistance of members to instability assessed by member checksn.

$\mathrm{Zg}$ : Position of the compressed neutral axis.

$\sigma_{c o m, E D}:$ The maximum compressive stress.

$\gamma:$ Density.

E: Young's modulus.

$f_{y a}:$ The increased average yield strength.

$\rho_{1,2}$ : The reduction factor.

$\psi$ : Ratio of moments in segment.

$K_{\sigma}$ : Plate buckling factor.

$\lambda$ : Reduced slenderness.

$b_{\text {eff } 1,2}$ : Effective width of the upper and lower sole (compressed and stretched).

$\lambda_{b p 1,2}$ : Reduced stretching of the upper and lower sole (compressed and stretched).

$A_{e f f}:$ Effective area of a cross section.

$Z_{c}:$ Position of the tensioned neutral axis.

$I_{\text {eff }, y}$ : Effective moment of inertia with respect to the axis (yy).

$W_{e f f, y}:$ Modulus of resistance cross section.

$\mathrm{K}:$ Numerical coefficient depending on the type of forming.

$\varepsilon:$ Factor depending on fy. 
$\varnothing$ : Inclination angle of the web relative to the flanges.

$f_{\max }$ : Maximum deflection.

$f_{\text {adm }}:$ Admissible deflection.

$M_{C, R d}$ : The calculation value of flexural strength with respect to a main axis of the section.

$M_{E d}$ : The bending moment at the ultimate limit state.

$V_{s d}$ : Shearing force at the ultimate limit state.

P: Concentred load

$V_{p l, R d}$ : Design value of the plastic shear strength.

$\mathrm{V}_{\mathrm{sd}}$ : Shear force in the ultimate limit state.

\section{REFERENCES}

[1] Sumathi, A., Babu, M.C. (2017). Flexural behavior of cold formed steel i-section beam with corrugated web, ASIAN J. Civ. Eng., 18(1), pp. 31-38.

[2] Reza, W., Senthil Selvan, S. (2016). Experimental Study on Flexural Behaviour of Cold Formed Steel Channel and I Sections Providing Angle Stiffener on the Web, Indian J. Sci. Technol., 9(35), DOI: $10.17485 / \mathrm{ijst} / 2016 / \mathrm{v} 9 \mathrm{i} 35 / 95967$.

[3] Mansuri, S., Parmar, K.A. (2017). Numerical Investigation of Flexural Strength of Cold Form Built-Up Beams, Int. J. Adv. Res. Sci. Eng., 6(1), pp. 109-116.

[4] Prakash, P.S., Samuel, J., Joanna, P.S., Sakaria, P.E. (2014). Flexural Behavior of Cold Formed Steel Beams with end Stiffeners and Encased Web, Int. J. Eng. Res. Technol., 3(11), pp. 1276-1279.

[5] Khadavi., Tahir, M.M. (2017). Prediction on flexural strength of encased composite beam with cold-formed steel section, AIP Conf. Proc. 3rd Int. Conf. Constr. Build. Eng., 1903, pp. 020016-1-020016-6, DOI: $10.1063 / 1.5011496$.

[6] Sureshbabu, S., Senthilselvan, S. (2019). Experimental Investigation on the Flexural Behaviour of Cold Formed Corrugated Steel Channel Sections, Int. J. Innov. Technol. Explor. Eng., 8(6S3), pp. 124-132.

[7] Sudharsan, S., N, V.K. (2018). Experimental Investigation of Cold-Formed Steel Composite Beams with Shear Connectors, Int. Adv. Res. J. Sci. Eng. Technol., 5(4), pp. 28-38, DOI: 10.17148/IARJSET.2018.546.

[8] Divahar, R., Joanna, P.S. (2016). Investigation on the behaviour of encased cold-formed steel beam with trapezoidally corrugated web, Int. J. Chem. Sci., 14(S1), pp. 10-16.

[9] Sivaranjani, S., Nalini, S., Annapurani, M. (2018). Flexural behaviour of cold form steel sections subjected to static loading, Int. J. Civ. Eng. Technol., 9(3), pp. 969-976.

[10] Morkhade, S.G., Baswaraj, S.M., Nayak, C.B. (2019). Comparative study of effect of web openings on the strength capacities of steel beam with trapezoidally corrugated web, Asian J. Civ. Eng., 20(8), pp. 1089-1099, DOI: 10.1007/s42107-019-00166-6.

[11] Abbas, H.H., Sause, R., Driver, R.G. (2006). Behavior of Corrugated Web I-Girders under In-Plane Loads, J. Eng. Mech., 132(8), pp. 806-814, DOI: 10.1061/(asce)0733-9399(2006)132:8(806).

[12] Preethi, T., Rajkumar, P.R.K., Jegan, M. (2020). Investigation on the Flexural Behaviour of Steel Cold Formed Built Up Sections, Int. J. Integr. Eng., 12(9), pp. 184-190, DOI: 10.30880/ijie.2020.12.022.

[13] Gatheeshgar, P., Poologanathan, K., Gunalan, S., Nagaratnam, B., Tsavdaridis, K.D., Ye, J. (2020). Structural behaviour of optimized cold-formed steel beams, Steel Constr., 13(4), pp. 294-304, DOI: 10.1002/stco.201900024.

[14] Shlyakhin, D., Lukin, A. (2016). A flexible beam with corrugated web and its performance under bending: an experimental study, MATEC Web Conf. 5th Int. Sci. Conf. Integration, Partnersh. Innov. Constr. Sci. Educ., 86, pp. 01009, DOI: $10.1051 /$ matecconf/20168601009.

[15] CEN (European Commitee for Standardization). (2003). Eurocode 3 Design of steel structures, Part 1.3 Gen. Rules Supplemary Cold Form. Thin Gauge Members Sheeting.

[16] Liu, Q. (2012). Structural analysis and design of cold formed steel sigma purlins. Doctoral thesis, University of Birmingham, Royaume-Uni.

[17] Ye, J., Mojtabaei, S.M., Hajirasouliha, I., Shepherd, P., Pilakoutas, K. (2018). Strength and deflection behaviour of coldformed steel back-to-back channels, Eng. Struct., 177, pp. 641-654, DOI: 10.1016/j.engstruct.2018.09.064. 
[18] Morkhade, S.G., Shaikh, S., Kumbhar, A., Shaikh, A., Tiwari, R. (2018). Comparative study of ultimate load for castellated and plain-webbed beams, Int. J. Civ. Eng. Technol., 9(8), pp. 1466-1476.

[19] Boursas, F., Boutagouga, D. (2021). Parametric study of I-shaped shear connectors with different orientations in pushout test, Frat. Ed Integrità Strutt., 57, pp. 24-39, DOI: 10.3221/IGF-ESIS.57.03.

[20] Dar, M.A., Subramanian, N., Dar, A.R., Anbarasu, M., Lim, J.B.P., Atif, M. (2018). Behaviour of partly stiffened coldformed steel built-up beams : Experimental investigation and numerical validation, Adv. Struct. Eng., 22(1), pp. 172186, DOI: $10.1177 / 1369433218782767$.

[21] Namdar, A., Dong, Y., Liu, Y. (2019). Timber beam seismic design - A numerical simulation, Frat. Ed Integrità Strutt., 47, pp. 451-458, DOI: 10.3221/IGF-ESIS.47.35.

[22] Jafari, F., Badarloo, B. (2019). Behavior of sandwich panels with different concrete material in two, Frat. Ed Integrità Strutt., 50, pp. 209-230, DOI: 10.3221/IGF-ESIS.50.18.

[23] Somadasa Wanniarachchi. (2005).flexural behavior and design of cold- formed steel beams with rectangular hollow langes. Doctoral thesis, Queensland University of Technology (QUT), Brisbane, Australia.

[24] Adel, B., Noureddine, F., Mohcene, B., Mesbah, H.A. (2020). Technique , proposed as an alternative to NSM and EBR techniques, Frat. Ed Integrità Strutt., 54, pp. 21-35, DOI: 10.3221/IGF-ESIS.54.02.

[25] Maali, M. (2019). Experimental and Numerical Prediction of Torsional Behavior of Steel Beam with Sinusoidal Web, Iran. J. Sci. Technol. Trans. Civ. Eng., 44, pp. 1-10, DOI: 10.1007/s40996-019-00304-9.

[26] Divahar, R., Joanna, P.S. (2018). Numerical simulation and experimental investigation on static behavior of cold formed steel beam with trapezoidally corrugated web by varying depth-thickness ratio, Asian J. Civ. Eng., 19(2), pp. 121-137, DOI: $10.1007 /$ s42107-018-0012-9.

[27] Nivedha, D.G.S., Yamini, V., Thalapathi, E. (2021). Design of Plate Girder with Corrugated Web, Turkish J. Comput. Math. Educ., 12(7), pp. 533-538. 